
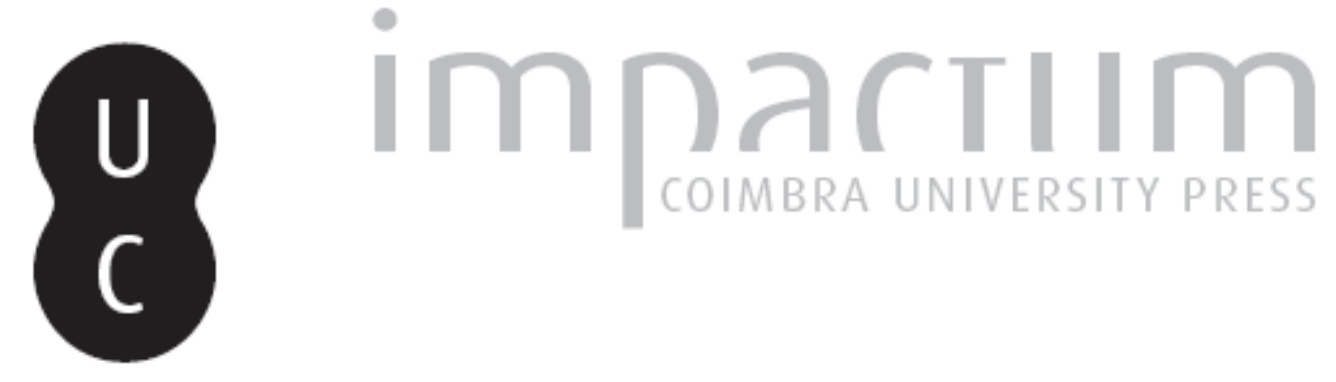

\title{
'Vê-los e ouvi-los': paisagens acústicas, olfactivas e culinárias nos Tratados da Terra e Gente do Brasil (1583-1601), de Fernão Cardim
}

\author{
Autor(es): $\quad$ Puga, Rogério Miguel
}

Publicado por: Centro de História da Sociedade e da Cultura

URL persistente:

URI:http://hdl.handle.net/10316.2/39364

DOI:

DOI:http://dx.doi.org/10.14195/1645-2259_14_6

Accessed : $\quad$ 26-Apr-2023 07:19:50

A navegação consulta e descarregamento dos títulos inseridos nas Bibliotecas Digitais UC Digitalis, UC Pombalina e UC Impactum, pressupõem a aceitação plena e sem reservas dos Termos e Condições de Uso destas Bibliotecas Digitais, disponíveis em https://digitalis.uc.pt/pt-pt/termos.

Conforme exposto nos referidos Termos e Condições de Uso, o descarregamento de títulos de acesso restrito requer uma licença válida de autorização devendo o utilizador aceder ao(s) documento(s) a partir de um endereço de IP da instituição detentora da supramencionada licença.

Ao utilizador é apenas permitido o descarregamento para uso pessoal, pelo que o emprego do(s) título(s) descarregado(s) para outro fim, designadamente comercial, carece de autorização do respetivo autor ou editor da obra.

Na medida em que todas as obras da UC Digitalis se encontram protegidas pelo Código do Direito de Autor e Direitos Conexos e demais legislação aplicável, toda a cópia, parcial ou total, deste documento, nos casos em que é legalmente admitida, deverá conter ou fazer-se acompanhar por este aviso.

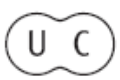




\section{4 \\ 2014}

\section{evista de História da Sociedade e da Cultura}

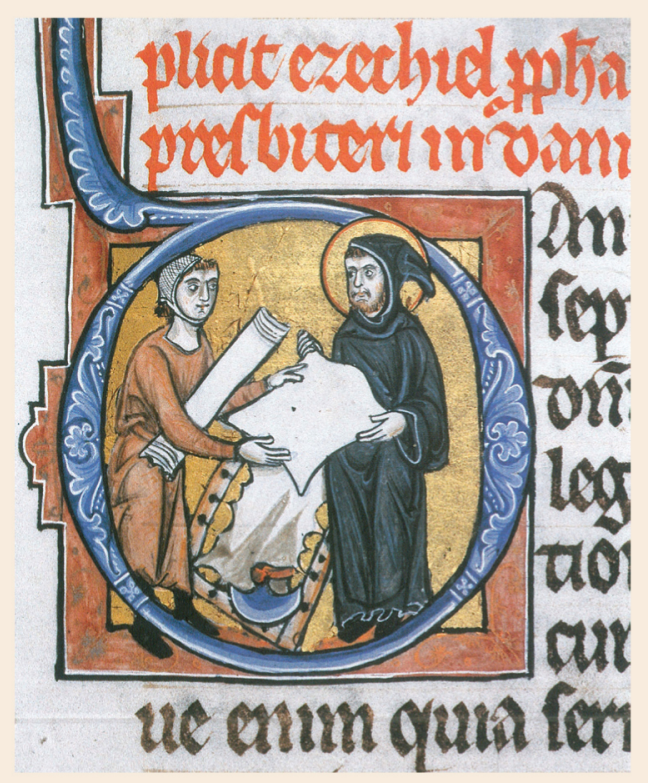

Centro de História da Sociedade e da Cultura Universidade de Coimbra 


\title{
'Vê-los e ouvi-los': Paisagens acústicas, olfactivas e culinárias nos Tratados da Terra e Gente do Brasil (1583-1601), de Fernão Cardim
}

\author{
Rogério Miguel Puga \\ FCSH, Universidade Nova de Lisboa \\ rogerio_puga@hotmail.com
}

Texto recebido em/Text submitted on:01.06.2014

Texto aprovado em/Text approved on: 09.10.2014

Resumo/Abstract:

Os Tratados do Brasil, redigidos entre 1583 e 1601 pelo Padre Fernão Cardim (c.1548-1625), apresentam ao leitor europeu a fauna, a flora e os usos e costumes dos índios brasileiros na última metade do século XVI, bem como episódios da interacção destes com os missionários europeus. Os tratados e as missivas ocupam-se ainda das paisagens acústicas, olfactivas e culinárias que compõem o espectáculo etnográfico da alteridade revelado ao leitor europeu, pelo que nos deteremos nessas mesmas paisagens que complementam a paisagem (visual) brasileira ao longo dos textos cardinianos.

The Tratados do Brasil (Treaties of Brazil), written between 1583 and 1601 by Father Fernão Cardim (c.1548-1625), provide the European reader with an image of the Brazilian fauna, flora and costumes of the indians in the late sixteenth century, as well as their interaction with European missionaries. The treaties and letters also represent the sound/smell and foodscapes that constitute the ethnographic show of Otherness revealed to the reader by the religious author, and this article deals with what the author heard (soundscapes), smelt (smellscapes) and savoured (foodscapes) in Brazil and also recreated to complement the different (visual) landscapes throughout his texts.

Palavras chave/Keywords:

Fernão Cardim; Tratados do Brasil; Paisagens acústica, olfactiva e culinária.

Fernão Cardim; Treaties of Brazil; Soundscape, smellscape, foodscape. 
Ao analisarmos relatos de viagem, normalmente detemo-nos na paisagem visual, no que o autor-viajante (relata que) viu. No entanto, e embora menos estudadas, existem outras paisagens ou dimensões a analisar nessas narrativas que revelam o espectáculo da alteridade ao leitor, pelo que, ao longo deste estudo, nos ocuparemos das paisagens acústicas (soundscapes), olfactivas (smellscapes) e culinárias (foodscapes), ou seja, dos sons, aromas e sabores que Fernão Cardim (c.1548-1625) descreve e sugere nos seus Tratados da Terra e Gente do Brasil, redigidos no Brasil, entre 1583 e 1601, dimensões auditivas e olfactivas que também contribuem para o estudo da história natural do Brasil; ${ }^{1}$ daí que Ana Maria de Azevedo apresente o referido missionário como simultaneamente botânico, etnólogo, geólogo, zoólogo e naturalista. ${ }^{2}$ Como recorda C. Almaça, a expansão portuguesa suscita a curiosidade sobre a fauna e a flora, e a par da motivação utilitária (a busca de novos recursos) herdada da tradição medieval, certas obras renascentistas indicam "já uma certa investigação sobre a estrutura e classificação natural dos animais". ${ }^{3}$ Esses processos de busca e de textualização da alteridade são obviamente operados através dos cinco sentidos, embora se estude sobretudo a paisagem visual em detrimento das paisagens olfactivas, acústicas, culinárias ou a do tacto. $\mathrm{O}$ presente estuda analisa assim a representação dessas quatro paisagens nos textos cardinianos.

Do Clima e da Terra do Brasil e de Algumas Coisas Notáveis que se Acham assim na Terra como no Mar (CTB) é um tratado enciclopédico sobre a fauna, a flora e os índios brasileiros, pelo que o texto é dividido em secções curtas com títulos auto-explicativos, como se fossem entradas de uma enciclopédia. A representação do Outro é muitas vezes feita ainda sob os efeitos do espanto perante o espectáculo da alteridade, servindo a escrita para ajudar a descodificar e sistematizar a informação relativa a paisagens estranhas e ainda relativamente incompreensíveis; aliás o próprio Cardim

1 Veja-se O'BRIEN, Maria Joaquina Pires - An essay on the history of natural history in Brazil, 1500-1900. Archives of natural history. 20 (1993) 37-48.

2 AZEVEDO, Ana Maria de - Introdução in CARDIM, Fernão - Tratados da terra e gente do Brasil. Lisboa: CNCDP, 1997, p. 9. Todos os textos de Cardim que citaremos foram publicados no referido volume, e indicaremos a paginação dessa edição no nosso texto principal, entre parêntesis.

3 ALMAÇA, Carlos - Os portugueses do Brasil e a zoologia pré-lineana, in AA.VV. A universidade e os Descobrimentos. Lisboa: INCM-CNCDP, 1993, p. 175-194. 
confessa, na sua primeira carta (16-10-1583), o quanto se espanta no Brasil através de expressões como "outra coisa que me espantou não pouco" ou "é cousa não somente nova, mas de grande espanto" $(225,236)$. Como veremos, a estratégia narrativa privilegiada pelo autor para narrar o Outro é a descrição assente na comparação, na adjectivação e na enumeração, ficando sempre implícito nesse acto de representação de uma realidade desconhecida as limitações, os conhecimentos e o olhar do viajante, bem como o processo de selecção da informação que é introduzida na narrativa e ainda tudo o que permanece fora do texto. Aliás, Cardim chama a atenção do leitor para esse processo, defendendo-se de eventuais críticas ao caracterizar o seu trabalho como representativo e não exaustivo: "e deixo outras muitas particularidades que têm no comer e no beber, porque estas são as principais" (169). Torna-se, portanto, crucial conhecer o contexto de produção da obra, bem como o da sua recepção pelos leitores europeus na segunda metade do século XVI e no início do século XVII, receptores esses implícitos ou implicados no processo da escrita e no texto em si, e que podemos inferir ou caracterizar através das explicações, comparações e contextualizações culturais que o autor faz ao longo da narrativa para permitir ao leitor português visualizar, cheirar e saborear as espécies, os objectos e os costumes que a obra tenta descodificar e registar. A título de exemplo, recorde-se a comparação entre rios brasileiros e portugueses ("três rios caudais tamanhos ou maiores que o Mondego de Coimbra", 224), a referência à ave Macucaguá, também feita por Pêro de Magalhães Gândavo na História da Província de Santa Cruz ${ }^{4}$ ("esta ave é maior que nenhuma galinha de Portugal; parece-se com faisão, e assim lhe chamam os Portugueses", 90), ou a descrição do Tapiti ("este animal se parece com os coelhos de Portugal", 76). Curioso é também o facto de, na década de oitenta do século da chegada dos portugueses ao Brasil, o autor, ao descrever a paisagem local, apresentar os coqueiros como parte da mesma ("Neste Brasil há muitos coqueiros, que dão cocos excelentes como os da Índia", 99), sem referir que essa espécie foi introduzida no Brasil pelos lusos, ou seja, é uma das inúmeras plantas deslocadas de um continente para

${ }^{4}$ GÂNDAVO, Pêro de Magalhães - História da província de Santa Cruz in ALBUQUERQUE, Luís de (dir.) - O reconhecimento do Brasil. Lisboa: Alfa, 1989 [1576], p. 93. 
o outro, fenómeno (adaptação e transformação das paisagens coloniais) que é actualmente estudado no âmbito da área de saber chamada 'imperialismo ecológico'. ${ }^{5}$ Aliás $C T B$ termina com um longo capítulo que lista e comenta os "animais, árvores, ervas, que vieram de Portugal e se dão no Brasil", e conclui "Este Brasil é já outro Portugal... pelas comodidades que de lá lhe vêm" (157-158). Como o tratado revela, animais como o cão são também levados para o Brasil e estimados pelos índios (159), passando os seus sons a fazer parte da paisagem acústica do território.

O título da obra conjunta publicada em 1925 e os títulos das primeiras partes - CTB e Do Princípio e Origem dos Índios do Brasil e de seus Costumes, Adoração e Cerimónias (POIB) - estabelecem um contrato de leitura assente nas curiosidades naturais e humanas ou etnográficas do Brasil. Para veicular todas as novidades, o autor serve-se de estratégias como a comparação, figura retórica de que a narrativa se encontra saturada, ${ }^{6}$ a identificação e a listagem de sons produzidos por animais e por humanos através do corpo e de utensílios do quotidiano. No início do século XVII, a imagem do índio brasileiro e das realidades etnográfica e natural era naturalmente diferente das representações iniciais, sendo importante reunir e sistematizar informação fidedigna, como Cardim faz ao dividir o seu texto em capítulos ou secções de acordo com os vários tipos de animais, frutos, plantas, árvores e as suas utilizações. Aliás, o autor assume-se como pioneiro na medida em que muitas das espécies naturais que descreve, e logo os seus sons e cheiros, são referidos pela primeira vez na sua narrativa. ${ }^{7}$

Se é óbvio que as fronteiras entre o Self e o exótico são físicas, políticas e culturais, estas são percepcionadas visualmente, mas também acústica e olfactivamente, por exemplo, as paisagens culinárias, para mencionar apenas

5 Veja-se CROSBY, Alfred W. - Ecological imperialism: The biological expansion of Europe. 900-1900, Nova Iorque: Cambridge University Press, 1986. Sobre o referido fenómeno no império português, veja-se FERRÃO, José Eduardo Mendes - A aventura das plantas e os Descobrimentos portugueses. Lisboa: IICT-CNCDP, 1994.

6 A título de exemplo, referimos o uso de quatro comparações sucessivas para um mesmo fruto ao longo de apenas duas linhas: "a fruta é como grandes laranjas, e se parece com marmelos, ou peras pardas; o sabor é de marmelo" (106).

7 Vejam-se as inúmeras notas de rodapé de AZEVEDO, Ana Maria na sua edição de Fernão Cardim, Tratados ..., cit., p. 68, 73-82, 86-87, 91-98, 103, 105-112, 118-125, 128 , 131-132, 138, 144-150, 155, 166. 
alguns dos elementos culturais que dão origem à sensação de exotismo, pois como refere Peter Mason, "the exotic... is not something that exists prior to its 'discovery'. It is the very act of discovery which produces the exotic as such... As a construct, the exotic is always up for renegotiation, as an invention, it is always open to reinvention". ${ }^{8}$ Estamos assim, como veremos, perante um testemunho que faz parte da chamada (proto-)etnografia ultramarina ou proto-Antropologia portuguesa, ${ }^{9}$ pois descreve - na medida do possível ao autor no final do século XVI, e com base em escritos anteriores e até comparações interculturais - especificidades culturais e ecológicas do Brasil de então.

\section{$O$ autor, a viagem e o(s) texto(s)}

O Padre Fernão Cardim ingressa na Companhia de Jesus em 1556, estuda em Évora e parte para o Brasil em Março de 1583, como secretário do Visitador Cristóvão de Gouveia, chegando ao destino em Maio desse ano, e aí permanece durante cerca de quarenta e dois anos, desempenhando vários cargos no seio da Companhia de Jesus. ${ }^{10}$ Cardim chega ao Brasil no

8 MASON, Peter - Infelicities: representations of the exotic. Baltimore: The John Hopkins University Press, 1998, p. 1.

9 Cf. GONÇALVES, José Júlio - Contribuição dos missionários para o desenvolvimento da Antropologia. Studia. 53 (1994) 103-108. Vejam-se também os estudos de HODGEN, Margaret T. - Early Anthropology in the sixteenth and seventeenth centuries. Filadélfia: University of Pennsylvania Press, 1971; HUBER, M. T. - Christianity in BARNARD, A. e SPENCER, J. (eds.) - Encyclopedia of Social and Cultural Anthropology. Londres: Routledge, 1996, p. 96-98, e BARRETO, Luís Filipe - Descobrimentos e Renascimento: formas de ser e de pensar nos séculos XV e XVI. Lisboa: IN-CM, 1983, p. 178, onde o autor aborda o conceito de "etnologia prática". Já PERRONE-MOISÉS, Leyla - Vinte luas. Viagem de Paulmier de Gonneville ao Brasil 1503-1505. São Paulo: Companhia das Letras, 1992, p. 103-4, ao comparar o relato de Gonneville com a Carta de Caminha, afirma: "As descrições dos tupiniquins/tupinambás... são preciosas... Considerá-las como textos de etnólogos é, no entanto, excessivo. Ambos procedem segundo o costume do seu tempo, dentro de um gênero já codificado na literatura de viagem, a descrição de povos com as suas roupas, suas armas e adereços, distinguindo cuidadosamente o homem e a mulher. Na falta de roupas, atentam para a pintura corporal; dão grande relevo ao que levam na cabeça, à guisa de chapéu."

${ }^{10}$ Sobre o Padre Fernão Cardim, vejam-se RODRIGUES, José Honório - História da História do Brasil, parte 1. São Paulo: Companhia Editora Nacional, 1979, p. 265ss; GARCIA, Rodolfo - Introdução in CARDIM, Fernão - Tratados da Terra e Gente do Brasil. São Paulo: Itatiaia-Edições, 1980; AZEVEDO, Ana Maria de - O Padre Fernão Cardim (1548-1625), 
período em que o território assume uma maior importância económica, com o apogeu da cultura da cana sacarina, a expansão territorial e a redefinição de fronteiras e de índios aliados e inimigos. ${ }^{11}$ Essa exploração dá lugar à descoberta de novas espécies de plantas e de animais, bem como dos seus usos, como o próprio Cardim refere várias vezes (104, 108, 120, 137).

$\mathrm{O}$ autor regressa à Europa, nomeadamente a Bruxelas e a Roma, como Procurador da Província do Brasil entre 1598 e 1601, sendo capturado por corsários ingleses ao regressar ao Brasil, ainda na barra de Lisboa, e aprisionado em Gatehouse (Londres), entre Dezembro de 1601 e Março de 1603. São-lhe retirados os seus escritos sobre o Brasil que Samuel Purchas publica mais tarde em inglês, com o título "A Treatise of Brasil written by a Portuguese which has long lived there", na colectânea Hakluytus Posthumus or Purchas his Pilgrimes (1625), narrativa caracterizada como a mais completa sobre o Brasil que chegara a Inglaterra até então. O seu autor foi identificado erradamente como sendo o irmão Manuel Tristão (1546-1631?), enfermeiro do Colégio da Baía que assinara receitas medicinais nas últimas páginas do manuscrito roubado pelos ingleses.

A primeira obra de Cardim a ser publicada é a Narrativa Epistolar de Uma Viagem e Missão Jesuítica pela Baía, Ilhéus, Porto Seguro, Pernambuco, Espírito Santo, Rio de Janeiro, S. Vicente (S. Paulo), etc., desde o ano de 1583 ao de 1590, indo por Visitador o Padre Cristóvão de Gouveia (NE), ${ }^{12}$ em 1847, por Francisco Adolfo Varnhagen. As duas missivas são redigidas por Cardim enquanto secretário do Visitador Cristóvão de Gouveia e são dirigidas ao Provincial de Assistência de Portugal. A primeira carta (16-10-1585) é dirigida ao padre Sebastião de Morais, que fora nono Provincial (1580-1588), e a segunda, também assinada no Colégio da Baía (01-05-1590), é dirigida ao Padre João Correia, que fora décimo Provincial.

dissertação de mestrado. Lisboa: Universidade de Lisboa, 1995 e AZEVEDO, Ana Maria de - Introdução..., cit., p. 9-18.

${ }^{11}$ Vejam-se COUTO, Jorge - A construção do Brasil. Lisboa: Cosmos, 1997, p. 273-308 e SANTOS, João Marinho dos - A integração do Brasil no império colonial português. Revista Portuguesa de História. 33:1 (1999) 93-94.

${ }^{12}$ Sobre outras cartas, veja-se MAGALHÃES, Pablo António Iglesias e PARAÍSO, Maria Hilda Baqueiro (ed.) - Cartas de Padre Fernão Cardim (1608-1618). Clio: Revista de Pesquisa Histórica. 27:2 (2009) 206-246. 
Mas apenas em 1881 Capistrano de Abreu reivindicaria para Cardim a autoria desses textos ao publicar POIB. Em 1885, Capistrano de Abreu publica, na Revista Mensal da Secção da Sociedade de Geografia de Lisboa do Rio de Janeiro, o texto integral de CTB e um estudo que identifica Cardim como o autor desses textos. Em 1925, quando das comemorações do terceiro centenário da morte de Cardim, ambas as narrativas são publicadas, juntamente com as duas missivas de 1585 e de 1590, que formam a chamada Narrativa Epistolar, com um só título Tratados da Terra e Gente do Brasil (Rio de Janeiro, Editores J. Leite, introdução e notas de Baptista Caetano, Capistrano de Abreu e Rodolfo Garcia). Das quatro narrativas que compõem a obra de Cardim, as duas primeiras são descrições das paisagens naturais e humanas do Brasil, sem qualquer referência aos movimentos do autor que lhe permitem observar, ouvir e cheirar os elementos por si textualizados, enquanto as duas cartas da $N E$ se aproximam do relato típico de memórias de viagem, pois a escrita retrospectiva, marcada por resumos e elipses, acompanha o movimento cronotópico e o olhar do viajante, bem como o seu espanto e as suas descobertas durante o encontro-confronto com o Outro íncola.

\section{Representações das paisagens acústicas e olfactivas brasileiras}

Como sugere a expressão da obra de Cardim (185) que dá título ao nosso estudo, analisaremos sobretudo as paisagens acústica, olfactiva e culinária nas narrativas de que nos ocupamos. Se quem observa, cheira, ouve e sente acumula aprendizagens através de todos os sentidos, não poderemos apenas determo-nos nas paisagens visuais, pois o autor-narrador também descreve o que ouve quando pouco ou nada consegue observar. Trata-se, portanto, de uma forma de compensar a falta de paisagem visual ou de a complementar, desejando, por vezes, Cardim apenas representar um fruto ou árvore como deveras aromáticos, pois essa é uma das principais características da espécie e, logo, uma das melhores formas de os nativos e os portugueses a identificarem. Analisaremos também a (representação da) componente audível dos rituais dos índios, desde a recepção de hóspedes às festividades antropofágicas. 
Os três tipos de paisagem que estudaremos nos tratados e epístolas de Cardim - soundscape, ou imagem sonora, smellscape, ou imagem olfactiva e foodscape, ou imagem culinária - são conceitos relativamente recentes no âmbito das ciências sociais e humanas. A imagem sonora pode ser definida como o conjunto de sons 'descritos', sugeridos e/ou reproduzidos num texto-fonte, ${ }^{13}$ tendo esse conceito sido cunhado por Raymond Murray Schafer (1933-), com base no termo landscape, no âmbito da sua investigação na área da ecologia acústica [The new soundscape (1969), The soundscape: our sonic environment and the tuning of the world (1977)]. O termo remete para os elementos sonoros presentes numa narrativa, nomeadamente sons humanos (vozes e música), naturais (clima e fenómenos naturais) ou animais, entre outros. A soundmark literária, como veremos no que diz respeito ao Brasil de Quinhentos representado nas narrativas cardinianas, encontra-se associada a sons típicos de um dado período numa zona geográfica específica, e, de acordo com Emily Ann Thompson, ${ }^{14}$ "like a landscape, a soundscape is simultaneously a physical environment and a way of perceiving that environment". Poderá tratar-se de uma paisagem sonora local ou regional que mapeia os ruídos e sons típicos de toda uma "nação" de índios. A soundscape e os padrões repetitivos dos Tratados, como as danças e músicas escutada pelos padres, relacionam-se também com os estados mentais das 'personagens', enquanto sons - alguns dos quais portugueses, pois são produzidos por instrumentos levados pelos religiosos - e cheiros são adjectivados pelo missionário $(95,120,127,172-173,178-179,184-185$, 221-223, 228, 232-235, 240-251, 257-260), e a audição é exacerbada pelas vicissitudes do convívio num território exótico, relativamente desconhecido e selvagem, que urge 'domesticar'. Interessam-nos sobretudo os enredos sonoros e aromáticos, ou seja, os acontecimentos percepcionados pela audição e pelo olfacto das personagens que escutam paisagens acústicas;

${ }^{13}$ PUGA, Rogério Miguel - 'Every Fresh Object Was Amusing': Representações sonoras de Portugal em Travels through Portugal and Spain, during the Peninsular War (1820), de William Graham in VICENTE, A. P. P. (coord.) - XX Colóquio de História Militar. A Guerra Peninsular em Portugal (1810-1812) vol. 1. Lisboa: Comissão Portuguesa de História Militar, 2012, p. 223-234.

14 THOMPSON, Emily Ann - The soundscape of modernity: architectural acoustics and the culture of listening in America, 1900-1933. Cumberland: MIT Press, 2004, p. 1. 
daí que R. Murray Schafer ${ }^{15}$ utilize a figura do viajante que procura objectos com interesse auditivo, a par dos objectos com interesse visual, como se verifica, até certo ponto, com o autor da obra de que nos ocupamos. Como veremos, a soundscape, ou sonografia, enquanto elemento simbólico e estruturante do texto, tem implicações sociais, estéticas, culturais e políticas ao concorrer quer para a caracterização do espaço (histórico-social) da acção e do sentimento de pertença de determinadas personagens, quer para práticas e comunidades específicas, assim como para a cultura do próprio autor.

Tal como os sons, também os aromas que constituem a paisagem olfactiva (smellscape) revelam actividades e presenças que, por vezes, o autor não pode ouvir nem observar, mas sim inferir através de cheiros. Num estudo sobre o olfacto, Jim Drobnick estende o conceito de soundscape para o campo da smellscape ao afirmar: "soundscapes consist of sound events, some of which are soudmarks (compare landmarks). Similarly, smellscapes will involve smell events and smell marks. 'Eyewitness' is replaced by 'earwitness' and nosewitness. Visual evidence becomes hearsay and nosesay. The heightening of visual perceptions becomes ear-cleaning and nose-training". ${ }^{16}$ A paisagem olfactiva poderá então ser entendida como o conjunto de aromas por vezes associados a pessoas, locais ou outros estímulos exteriore ${ }^{17}$ que intensificam a descrição da paisagem visual, que é, como sabemos, predominante na escrita de viagens. Os índios descritos por Cardim produzem ruídos que são partilhados e ouvidos por vizinhos, permitindo-nos analisar de que forma os autores europeus em geral ouvem e percepcionam o 'mundo novo' que os rodeia. As paisagens olfactivas e auditivas são, portanto, análogas à paisagem visual, remetendo para a informação geográfica percepcionada em conjunto pela visão, pela audição e pelo olfacto, que, por sua vez, auxiliam o ser humano a localizar-se a

${ }^{15}$ MURRAY, Schafer, R. - The soundscape: our sonic environment and the tuning of the world. Rochester: Destiny Books, 1993, p. 212.

${ }^{16}$ DROBNICK, Jim - The smell culture reader. Oxford: Berg, 2006, p. 92.

${ }^{17}$ RELPH, E - Place and placelessness. Londres: Pion, 1976; ENGEN, T. - The origin of preferences in taste and smell in KROESE, H. A. (ed.) - Preference, behaviour and chemoreception. Londres: Information Retrieval, 1979, p. 263-73; ENGEN T. - The perception of odors. Nova Iorque: Academic Press, 1982; ENGEN, T. e ROSS, B. M. - Long term memory of odors with and without verbal descriptions. Journal of experimental psychology 100 (1973) 221-27. 
si mesmo e a terceiros no espaço. Já Tuan ${ }^{18}$ e Porteous ${ }^{19}$ têm estudado a dimensão olfactiva da experiência geográfica, e este último utiliza o termo smellscape para aludir à dimensão geográfica de determinados aromas: "the concept of smellscape suggests that, like visual impressions, smells may be spatially ordered or place-related". ${ }^{20}$ Como veremos, enquanto a paisagem humanizada e natural percepcionada pela visão não muda de imediato, cheiros e sons aparecem, mais ou menos intensos, e vão-se esbatendo, e, no caso do cheiro, poderá inclusive impregnar-se. ${ }^{21}$ No que diz respeito ao mundo natural e até à natureza humanizada, a soundscape e a smellscape são por isso muito mais efémeras que a paisagem visual, uma vez que as construções físicas e as paisagens naturais não mudam repentinamente, como acontece com os aromas, que são, talvez por isso, muito menos referidos. A descrição da diversidade de paladares, aromas, formas, cores e usos dos frutos e plantas concorre para a construção do campo semântico da abundância, da diversidade e da fertilidade (114-122, 219, 227, 238, 243, 274-276), ou da "fartura" $(116,243,276)$ que se torna um festim para o sentidos do viajante e do residente, como Cardim demonstra ao descrever o ananás e as suas inúmeras qualidades medicinais e alimentares através da enumeração, da tripla adjectivação e da comparação:

a fruta é muito cheirosa, gostosa, e uma das boas do mundo, muito cheia de sumo e gostoso, e tem sabor de melão ainda que melhor, e mais cheiroso; é boa para doentes de pedra, e para febres muito prejudicial. Desta fruta fazem vinho os Índios muito forte, e de bom gosto. A casca gasta muito o ferro ao aparar e o sumo tira nódoas da roupa. Há tanta abundância desta frita que se cevam os porcos com ela. (114-115).

O abundante ananás é descrito como alimento ímpar devido às suas qualidades medicinais, ao seu sabor intenso e sumo abundante, e o excerto transcrito remete simultaneamente para o olfacto, o paladar, o tacto e

${ }^{18}$ TUAN, Yi-Fu - Topophilia. Prentice-Hall: Englewood Cliffs, 1974.

${ }_{19}$ PORTEOUS, J. D. - Smellscape. Progress in human geography 9:3 (1985) 356-78; PORTEOUS, J. D. - Landscapes of the mind: worlds of sense and metaphor. Toronto: University of Toronto Press, 1990.

${ }^{20}$ PORTEOUS, J. D. - Smellscape..., cit., p. 359.

${ }^{21}$ RODAWAY, P. - Sensuous geographies: body, sense and place. Nova Iorque: Routledge, 2002, p. 61-81. 
para a visão, funcionando o texto, como já afirmámos, como um catálogo ou repositório de usos medicinais e de mezinhas dos índios já adaptados pelos portugueses que lhe dão inclusive um novo uso: o ananás passa a ser utilizado como tira-nódoas. O recorrente tema da abundância, associado ao da diversidade, é recuperado inúmeras vezes ao longo dos textos, nomeadamente para descrever búzios e conchas que existem em "muita quantidade nesta terra... e de várias espécies" (146) ou a "infinidade de espécies" de gaivotas (149), sendo referida várias vezes a superioridade das espécies naturais brasileiras relativamente às portuguesas $(94,99,113,148$, $157,159,223)$, à excepção, por exemplo, das plantas de cheiro, porque o clima brasileiro, ao contrário do que acontece na Ásia, não estimula os seus aromas $(109,127-128)$. Esse topos da abundância, juntamente com o da alteridade, encontra-se presente na escrita de viagens portuguesa relativa ao Brasil desde o século XVI, sendo sugerido que a abundância é obra divina (224) e que o Brasil é terra abençoada. Esse exercício de intertextualidade que estabelece um diálogo entre as várias obras de autores portugueses sobre um mesmo território colonial é facilmente demonstrado através da abordagem comparatista, bastando convocar, a par da obra do Padre Cardim, por exemplo, a já referida História de Magalhães de Gândavo, na qual encontramos inúmeras formas de legitimar o que se descreve, "por ser coisa nova, e [ele] a escrever como testemunha de vista", uma vez que o Brasil era "diferente... e fora do comum". ${ }^{22}$ No segundo capítulo da História, o tópico da abundância é apresentado de forma clara e é posteriormente continuado ao longo da narrativa: "é esta província sem contradição a melhor para a vida d homem que cada uma das outras Américas, por ser comummente de bons ares e fertilíssima, e em grão maneira deleitosa e aprazível à vista humana", ideia desenvolvida, tal como nos Tratados de Cardim, através da adjectivação ("espesso arvoredo", "preciosas ribeiras", "fontes... infinitas", "[rio] mui grande"). ${ }^{23}$

A primeira paisagem de que nos ocuparemos será a culinária. $\mathrm{O}$ autor compara e refere duas foodscapes, a portuguesa e a brasileira $(94,112)$, fazendo parte desta última a carne humana (182-189). A paisagem culinária

${ }^{22}$ GÂNDAVO, Pêro de Magalhães - História..., cit., p. 69 e 72, respectivamente.

${ }^{23}$ GÂNDAVO, Pêro de Magalhães - História ..., cit., p. 74-75. 
encontra-se associada simultaneamente à vista, ao paladar e à medicina natural, relação que constatamos ao longo das descrições de frutos e das suas aplicações culinárias e medicinais (94-96, 98, 116, 116, doce, amargo), de especiarias e de cozinhados $(112,116-119,130-131,143,145,160,161)$. Os Tratados comparam ainda sabores exóticos a outros mais familiares do leitor português ["o gosto [da jaboticaba], parece de uva ferral" (98), ou "a casca... amarga mais que piorno, serve de sabão" (107)] e tentam encontrar explicações ecológicas para a diferença nos sabores de uma mesma espécie em Portugal e no Brasil, por exemplo do aipo: "acha-se somente nas praias, principalmente no Rio de Janeiro, e por esta razão é mais áspero, e não tem doce ao gosto, como o de Portugal: deve ser por causa das marés" (125). Cardim informa o leitor do uso quotidiano, medicinal, recreativo e religioso de inúmeros elementos das paisagens natural e etnográfica brasileiras, e se o autor recolhe dados de informantes locais (os índios), também se auto-caracteriza como investigador e viajante interessado e informado, que consulta estudos sobre a Ásia produzidos por colegas ibéricos, estabelecendo comparações entre espécies de vários continentes: "Iabigrandi. Esta árvore há pouco que foi achada, e é, como dizem alguns indiáticos, o Betele...; os Espanhóis usam dela e dizem que é tão boa como a da Índia" (104). Os peixes são também descritos com base no seu sabor, ou "bom gosto" (131-132, 137), e no facto de serem ou não "bons para comer" (136). É ainda curiosa a forma como os sabores e cheiros de diferentes mamíferos cozinhados, como a vaca e o porco, são replicados através de formas de cozinhar o peixe boi, que partilha características com esses dois animais, colocando, portanto, problemas nos dias em que os católicos não podem comer carne. A diversidade e abundância naturais do Brasil espantam o autor, sobretudo no que diz respeito à paisagem culinária ou foodscape, como o próprio confessa:

De uma cousa me maravilhei nesta jornada, e foi a grande facilidade que têm em agasalhar os hóspedes..., a qualquer hora da noite ou dia que chegávamos em brevíssimo espaço nos davam de comer ... todas as variedades de carnes, galinhas, perus, patos, leitões, e outras castas e tudo têm de sua criação, com todo o género de pescado e marisco de toda a sorte... e na fartura parecem uns condes, e gastam muito (244). 
Relativamente ao tacto, Cardim detém-se sobretudo na textura de madeiras, de cascas de fruto e de caules de plantas $(97,100,115-116,122,147)$, informação importante para a construção de estruturas e para o uso desse material pelos portugueses. Algumas árvores são descritas como "frescas" (97) e certas frutas como "dura[s] como pedra... e resplandecente[s], que parece[m] vidro" (102). Para o sentido do tacto, remete ainda indirectamente o capítulo da primeira parte "Dos óleos de que usam os índios para se untarem" (105), pois os índios "untam[-se]" com "azeite" quer como acto medicinal preventivo e curativo, quer com finalidades estetico-simbólicas: "E também fazem muitas galantarias pelo corpo, braços e pernas com este óleos, pintando-se" (105), prática associada pelo autor proto-etnógrafo à prática europeia do vestir (107). A atenção ao detalhe e o conhecimento sobre os costumes locais são transmitidos enquanto 'saber de experiência feito', também com base no saber livresco; daí que sejam referidos os talos moles e porosos (116) da bananeira, e as suas qualidades descritas através de advérbios, da comparação, da enumeração e da adjectivação (sobretudo no grau superlativo absoluto sintético). ${ }^{24}$ Essas estratégias veiculam sensações tácteis como a frescura e textura das folhas em que se deitam doentes: "todas rachadas como veludo de Bragança, tão finas que se escreve nelas, tão verdes, e frias, e frescas que deitando-se um doente de febres sobre elas fica a febre temperada com sua frialdade, são muito frescas para enramar as casas e frescas" (115-116), informação que é vital num território tropical. O tacto é ainda convocado quando se listam as formas de curar picadas de mosquitos (147-148), ao descrever a fase final do ritual do assassinato e da ingestão do inimigo, quando crianças revolvem as entranhas do cadáver (187) para retirar a sua refeição, ou ainda quando o corpo do jovem a tornar-se guerreiro é cortado com dentes de cutia como parte das cerimónias do ritual de iniciação, enquanto ele geme e grita (189-190). O campo semântico da dor e da crueldade é assim reforçado pela paisagem acústica do sofrimento e por comportamentos e valores que são materializados através de palavras, gestos e provas físicas, ou como o texto explicita, de "tormento[s]" (190),

\footnotetext{
24 "É cousa de muita alegria ver os muitos rios caudais e frescos bosques de altíssimos arvoredos, que todo o ano estão verdes e cheios de formosíssimos pássaros que em sua música nos dão muita avantagem os canários, rouxinóis e pintassilgos de Portugal” (223).
} 
bem como através do silêncio dias a fio com que termina o referido ritual de passagem ou de iniciação do futuro matador. O tacto e a dor são ainda sugeridos através das imagens do castigo corporal de crianças com "trombas" de peixes (133), a par da (explicação da) prática de lhes açoitar os pés com cardos "para se acostumarem a andar pelos matos bravos" (198).

O índio brasileiro é assim simultaneamente descrito por Cardim e produtor dessa descrição enquanto informante do autor, nomeadamente no que diz respeito aos nomes, aos usos e às características medicinais de árvores e plantas, como aliás o missionário informa amiúde ao informar o leitor: "Outros dizem que" (81), "que lhe chamam" (82), ou "aqui os Índios chamam" (132). São também incrustados vários outros registos no texto que se torna assim polifónico, ou seja, a várias vozes, como acontece quando o autor descreve as cantarias das idosas quando do ritual antropofágico e transcreve, traduzidos, dois excertos da cantiga que compara as mulheres a assassinas de pássaros quando o cativo não poderá voar para longe delas (185), logo essa mesma canção acentua, através da voz e da focalização femininas, o carácter cruel do ritual e da comunidade que o encena. Aliás, durante a descrição do ritual são várias as aproximações do ambiente que se observa, cheira e ouve ao inferno $(184-185,186)$, enquanto a ideia de caos e várias imagens grotescas são utilizadas para gerar uma certa repugnância crescente no leitor até ao momento da morte do inimigo, no qual o autor traduz e transcreve mais uma fala, a do índio que mata o cativo, bem como insultos que os nativos dirigem às vítimas europeias (186). São ainda traduzidas culturalmente e textualizadas, em forma de discurso directo, outras falas do ritual dirigidas ao "cavaleiro" índio que acaba de matar o inimigo (189), bem como falas em português de mulheres e meninos convertidos: "louvado seja Jesus Cristo" (222), tendo assim o leitor a sensação de um contacto mais próximo ou directo com as realidades e 'personagens' representadas. Para além das traduções, o autor toma ainda emprestados, como não poderia deixar de ser, inúmeros termos da língua quechua ou quíchua, mas sobretudo do tupi-guarani (língua de catequese), por exemplo topónimos e nomes de frutos, animais, plantas, árvores, instrumentos, nações ameríndias, zonas, rios e práticas que os portugueses aprendem com e herdam dos índios. Há, portanto, uma paisagem acustico-linguística 'nativa' na obra, embora escrita, sendo listados termos do tupi como "abaré" (padre jesuíta, 197). 
O autor assume-se como tradutor simultaneamente linguístico e cultural que se socorre dos préstimos de intérpretes por parte dos índios aliados dos portugueses para contactar e converter outras nações ameríndias (206-207), pelo que o texto termina com a imagem de um território fértil e diversificado em termos naturais, etnográficos e linguísticos, o que dificulta a valiosa e árdua tarefa da evangelização e exige simultaneamente uma continuada missão civilizadora.

Deter-nos-emos de seguida na paisagem acústica ou soundscape, que também permite a Cardim estabelecer comparações interculturais, pois a música que é harmoniosa para os índios não passa de ruído para o observador europeu (184), sendo a apresentação dessas diferenças culturais também uma forma de o autor se auto-distanciar e apresentar o íncola como selvagem ainda por civilizar (184), antes de conhecer o "seu Criador" (190).

Os sons ou a 'banda sonora' da antropofagia ritual dos povos Tupis, ${ }^{25}$ como as palmadas na boca, as danças e festividades rituais e os gritos descritos nas páginas 182-189, na secção "Do modo que este gentio tem acerca de matar e comer carne humana" de $P O I B$, repetem-se em inúmeras descrições do ritual pela pena de outros autores europeus. A referida secção enumera a sucessão de fases do ritual antropofágico que dura vários dias, sendo alguns sons apenas sugeridos pelas actividades desenvolvidas, e outros claramente identificados, nomeadamente os insultos, as danças repetitivas ao som de gaitas de cana e pautadas por batimentos no chão que "fazem uma harmonia que parece música do inferno, mas eles aturam nela como se fossem as mais suaves do mundo; e estas são umas festas, afora outras que entremetem com muitas graças e adivinhações" $(184,187)$, seguindo-se lutas e "coro de ninfas", cuja canção Cardim, como já afirmámos, analisa através de comentários sobre a música e a letra (que cita), inscrevendo a voz do Outro na narrativa. A descrição dessas festividades serve o propósito de representar estrategicamente os costumes nativos como infernais e até escatológicos (185), caracterizados por uma carga semântica negativa. Aliás, na $N E$ (235),

${ }^{25}$ Sobre os rituais antropofágicos, vejam-se, entre outros: FERNANDES, Florestan - A função social da guerra na sociedade Tupinambá, São Paulo: Museu Paulista, 1952; CASTRO, Eduardo Viveiros de - Arewetê. Os deuses canibais. Rio de Janeiro: Jorge Zahar, 1986, p. 316-349, 596-696, CUNHA, Manuela Carneiro da - Imagens dos índios do Brasil: o século XVI. Estudos Avançados USP 4:10 (1990) 108. 
o autor visualiza a casa dos nativos como um caos simultâneo de acções, sons e ruídos, conferindo um certo dramatismo à obra: "um inferno ou labirinto, uns cantam, outros choram, outros comem, outros fazem farinha e vinhos, etc. E toda a casa arde em fogos". Era, portanto, urgente ordenar e disciplinar, ou seja, catequizar "gentes tão bárbara", descritas já como mais ordeiras nas povoações visitadas por missionários, onde as crianças cantam “cantigas devotas”, imitam pássaros e encenam peças religiosas, enquanto os adultos saem à rua a dançar e a desfilar para receber o padre visitador "com grande grita e urros, que ... atroavam e [os] faziam estremecer" e a tocar flauta (221, vide p. 222, 228, 232-233, 239-241, 258-266). As inúmeras referências a momentos de lazer como danças, cantares, jogos e à catequização teatral e musical das crianças índias reforçam a ideia do sucesso da evangelização através dos nativos de tenra idade. Já "as cerimónias que se fazem ao novo cavaleiro" (189-190) demonstram a forma como os autores ocidentais transpunham para o território brasileiro conceitos e rituais europeus, sendo as sensações 'tactuais' e físicas do futuro guerreiro exacerbadas para veicular o sofrimento que ele suportou corajosamente durante as várias fases do ritual de iniciação.

No início de $C T B$ são sugeridos ao leitor os sons implícitos da paisagem natural do Brasil através de descrições enumerativas ou personificações que instauram e reforçam cumulativamente a ideia de abundância e fertilidade natural do território: "A terra é um tanto melancólica, regada de muitas águas, assim de rios caudais, como do céu, e chove muito nela" (63). Já os bugios distinguem-se nas árvores pelo

tamanho ruído que se ouve muito longe, no qual atura muito sem descansar, e para isso tem articular instrumento esta casta, o instrumento é certa cousa côncava como feita de pergaminho muito rijo..., e começa do princípio da guela até junto da campainha..., e é este instrumento tão ligeiro que em the tocando se move como a tecla de um cravo. E quando este bugio assim está pregando espuma muito. (75).

Os sons específicos de uma espécie servem para a caracterizar e dão lugar à descrição dos órgãos que permitem a esses animais produzir sons característicos e que são comparados a instrumentos musicais. A descrição de realidades desconhecidas exige assim o uso da comparação com realidades já familiares para permitir ao leitor visualizar ou imaginar a nova espécie 
e/ou o novo objecto em questão. Determinados sons são ainda relacionados com as crenças dos índios, pelo que a obra adquire também um cariz proto-etnográfico no que diz respeito à paisagem acústica brasileira: "Este animal se parece com o coelho de Portugal, estes ladram cá nesta terra como cães, maxime de noite, e muito a miúde. Os índios têm estes ladridos por agouro" (76-77). Também a paisagem olfactiva acentua a dimensão etnográfica do texto, pois Cardim refere a utilização das ervas com que os índios "se perfumam... doentes para não morrerem, e para certa enfermidade" (122), relacionando as qualidades medicinais e os aromas de determinadas ervas às crenças de nativos. A descrição de pássaros como a saracura centra-se também no canto e nas ilusões acústicas que o animal produz ao fazer-se passar por um pássaro de maior porte. O seu canto marca a passagem do tempo durante horas "e quando canta de ordinário adivinha bom tempo" (151), informação decerto veiculada aos portugueses pelos índios, bem como muitos outros dados sobre hábitos e a utilização de recursos e remédios naturais (156).

Como não poderia deixar de ser, as crenças dos índios estão associadas a sons naturais e a determinados animais, revelando Cardim, de forma hiperbólica, que os íncolas ao ouvir a rã guararieí morrem de tanto medo que têm do anfíbio: "tão grande é a imaginação, e apreensão, que tomam de a ouvir cantar; e qualquer índio que a ouve morre, porque dizem que deita de si um resplandor como relâmpago" (157). Há, portanto, também a descrição de um fenómeno a que poderíamos chamar 'imaginação acústica', sendo, mais uma vez, a voz do índio convocada e veiculada pela narrativa. Como já sugerimos, trata-se de um texto a várias vozes, embora a do autor português seja obviamente preponderante, e a do Outro filtrada e seleccionada por ele. $P O I B$ descreve ainda uma outra crença semelhante dos índios devido ao medo que têm do ‘demónio' Curupira, que só de o imaginarem falecem, “como aconteceu já muitas vezes” (166). Esta estratégia faz assim parte da caracterização premeditada dos índios como supersticiosos e sem religião, servindo as descrições dos sons de festas e associados à diversão em "bailes e música... vinhos" $(169,172)$ para os apresentar como alegres e festivos. Os sons estão ainda associados à Natureza, à mitologia nativa $(167,173)$ e aos costumes do grupo como a saudação lacrimosa em rituais funerários ou para receber hóspedes (173-175, 179, 236-238), tendo os padres ociden- 
tais introduzido novas práticas entre os nativos e com elas novos sons, por exemplo "contar, cantar e tanger" $(173,241)$ ao modo europeu, temáticas que se repetem nas narrativas cardinianas.

Os divertimentos dos índios descritos por Cardim são também associados a sons específicos, nomeadamente na secção "Dos seus bailos e cantos" (178-179), ruídos que fazem parte da paisagem acústica etnográfica da obra. Aliás, a referida secção assenta no campo semântico da diversão construído através da enumeração repetitiva de verbos como: arremedar, folgar, ouvir, chamar (nomes), jogar, desconcertar, pelejar, bailar, cantar, bater (de pés), andar e cantar, entre ouros termos como cantor, inventor de trovas, gatimanhas, momos, vozes, contraltos e tenores (178-179). Já a secção "diversidade de nações e línguas" ocupa um capítulo de $P O I B$ (192-206) ao longo do qual termos, sons, músicas e "estrondos" nativos são convocados de forma cumulativa e contextualizados, bem como a confissão, a oração e as pregações dos padres e dos índios, os diálogos destes em português e em língua nativa, a música e as invenções durante as festas, as missas e as procissões para cativar os índios (222-223, 232-234, 236, 240-251, 265), ou ainda orações de crianças em língua angolana (250) e conversas em língua tupi $(250,260,272)$, todas estratégias acústicas de evangelização; daí que o verbo 'ouvir', os nomes de instrumentos e os diversos sons sejam enumerados ao longo das descrições das festividades. Essas manifestações públicas das comunidades nativas são descritas como caóticas, mas fervorosas, e mesmo

as mulheres os acompanham, e os mais deles nus, e juntos andam correndo toda a povoação, dando grandes urros, e juntamente vão bailando, e cantando ao som de um cabaço cheio de pedrinhas (como os padeirinhos dos meninos em Portugal)... calcam o chão de maneira que fazem tremer a terra. Andam tão inflamados em braveza, e mostram tanta ferocidade, que é cousa medonha e espantosa... Não se lhes entende o que cantam, mas disseram-me os padres que cantavam em trova quantas façanhas e mortes tinham feito seus antepassados. (234-235).

Noutras alturas a música relaxante tem efeitos terapêuticos nos ouvintes (249), ficando claro que os estímulos auditivos externos influenciam quer os índios, quer os padres. Os sons humanos alternam com os da natureza selvagem, e a cobra cascavel e o seu ruído característico (82) marcam 
presença na obra, assim como os papagaios que são ensinados a falar pelos nativos (84-86), enquanto os tuins (psitacídeos pequenos) "fazem muitos momos, e sempre falam, ou cantam a seu modo" (87). Qualidades (próximas das) humanas, como a suposta fala, transformam esses animais em agentes de entretenimento para os índios, que os domesticam para diversão; aliás, é conferida grande atenção às diferentes formas de falar dos pássaros, como revela a entrada relativa à pombinha das almas ou gunhatá, cujo nome em tupi (guigranheéngetá) significa "pássaro que fala ou canta muito" e cuja descrição Cardim centra sugestivamente nos sons que emite: "é pássaro excelente para gaiola, por falar de muitas maneiras, arremedando muitos pássaros, e fazendo muito trocados e mudando a fala em mil maneiras, e atura muito em o canto, e são de estima" (89). Já o tangará (dançador) "tem um género de baile gracioso... um cantar de gritos estranhos que se ouve muito longe, e como acabam esta festa, grita" (89), enquanto o araponga ou ferreiro, cujo canto tem um tom metálico, é descrito como o "repique de sino" (90), som semelhante ao produzido pelos ovos do mutú quando batem uns nos outros, "e deles fazem os seus maracas" (91). A plêiade de sons naturais como que mimetiza os sons humanos ou produzidos por humanos. Há, portanto, também um exotismo acústico, que urge veicular ao público europeu como parte da descrição e descoberta do Outro. Aliás, o processo da captação da alteridade pelos diversos sentidos humanos é enfatizado quando o autor veicula o estranhamento do Outro, ${ }^{26}$ que é, por sua vez, textualizado através da adjectivação e da repetição da ideia de estranheza quer para os olhos, quer para os ouvidos: "É cousa não somente nova, mas de grande espanto, ver o modo que têm em agasalhar os hóspedes, os quais agasalham chorando por um modo estranho, e a cousa passa desta maneira." (236). A viagem rumo ao espectáculo da alteridade faz-se também rumo a novos aromas, ou seja, a exóticas paisagens aromáticas. Ao descrever a fauna e a flora brasileiras, Cardim não poderia deixar de referir cheiros específicos de certas espécies, bem como aromas associados a determinados locais, como acontece durante a representação dos porcos monteses que "têm o embigo nas costas e por ele saem um cheiro como de raposinhos, e por este cheiro o seguem os cães

${ }^{26}$ Vide FIGUEIREDO, José Ricardo - Modos de ver a produção do Brasil. São Paulo: Autores Associados, 2004, p. 33-44. 
e são tomados facilmente" (65). Estas descrições, de tão minuciosas que pretendem ser, associam aromas a sons, sendo algumas espécies nomeadas devido aos ruídos que produzem: "porque bate, e trinca os dentes" (67). Já o sarigué ou gamba é descrito com o recurso à comparação com as raposas espanholas e a gatos, sendo adicionada uma outra comparação ao nível olfactivo: "cheiram muito pior a raposinhos que as mesmas de Espanha" (68). Curiosidades como os sistemas de defesa de animais através de odores são minuciosamente descritos e até de forma hiperbólica, como acontece com a descrição do biarataca ou zorrilho, aproximado ao furão europeu e cuja secreção nauseabunda (sulfidrato de etila, ou mercaptan) afasta os inimigos:

é muito temido, não porque tenha dentes nem outra arma com que se defenda, mas dá certa ventosidade tão forte, e de tão ruim, que os paus, pedras, e quanto diante de si se acha, penetra, e é tanto que alguns índios morreram já de tal fedor, já cão que ele se achega não escapa, e dura este cheiro quinze, vinte e mais dias, e é tal que se dá esta ventosidade junto de alguma aldeia logo se despovoa para não serem sentidos, cavam no chão, e dentro dão a ventosidade, e a sua defensa é disparar aquela ventosidade. Há outras espécies destes animais que não têm tão mau cheiro, criam-se em casa, e ficam domésticos, e os Índios os estimam. (77-78).

Certas cobras, como as jararacas, fazem parte da paisagem olfactiva brasileira, e mesmo não sendo vistas denunciam a sua presença porque "cheiram muito a almíscar, e onde quer que estão dão sinal de si pelo bom e suave cheiro" (83), ou seja, o autor descreve não apenas o que no Brasil se pode ver e ouvir, mas também cheirar. As árvores de fruto são igualmente representadas através do aroma (sazonal ou constante) que as caracteriza, por exemplo a mangabeira, cuja flor é "como de jasmim, e de tão bom cheiro, mas mais esperto", sendo a descrição complementada por elementos de cariz culinário ("são de muito bom gosto, sadias e tão leves") ou tactual ("pega muito nas mãos", 95). Também as ervas medicinais são identificadas pelo seu aroma e procuradas por animais doentes através do olfacto (100), tendo essas informações origem nos índios, que se assumem assim como valiosos informantes dos portugueses no que diz respeito à exploração dos recursos naturais brasileiros. Esse estatuto dos nativos torna-se claro quando Cardim descreve o hábito de eles usarem a almecegueira como "incenso" 
para "se defumarem", sendo utilizada também pelos portugueses como “incenso branco" (102-103). Aliás, várias árvores são agrupadas como "madeiras de paus de cheiro" $(103,217)$ e os seus usos identificados, a par da intensidade dos seus cheiros e graus de maleabilidade. O autor destaca as ervas aromáticas através de duas breves secções chamadas "Das ervas cheirosas" $(127-128,161)$ que se assumem como um tema recorrente na narrativa, sendo curioso o facto de ele listar o sândalo branco e o pau de aguila quando essas madeiras não foram introduzidas no Brasil.

Como vimos ao longo deste trabalho, os Tratados encontram-se saturados de comparações entre o exótico brasileiro e o familiar europeu (75-77, 88, 90-91, 99), permitindo-nos o nosso estudo analisar as temáticas recorrentes dos sons, aromas e sabores brasileiros textualizados por Cardim e contextualizar essas mesmas presenças no âmbito da escrita de viagens portuguesa, à luz dos objectivos comunicativos do autor. A análise da representação das referidas paisagens revela especificidades e revisita a descrição multidimensional da relação dos índios e dos portugueses com determinadas espécies animais que fazem parte das paisagens ecológica(s) e etno-acústica brasileiras. A adjectivação, a comparação, a descrição enumerativa e o visualismo encontram-se assim ao serviço da textualização da alteridade do Outro, sobretudo através dos sons, dos aromas, dos sabores e das texturas a ele associados pelo texto e, através deste último, pelo leitor europeu. 